\title{
Ontogenetic Origins of Human Integer Representations
}

\author{
Susan Carey ${ }^{1} \&$ David Barner ${ }^{2,3}$ \\ ${ }^{1}$ Department of Psychology, Harvard University \\ ${ }^{2}$ Department of Psychology, University of California, San Diego \\ ${ }^{3}$ Department of Linguistics, University of California, San Diego
}

Word Count $=4003$ words

Correspondence: scarey@wjh.harvard.edu (S.E. Carey).

Keywords: Counting, Number, Magnitudes, Language, Conceptual Change

\section{Acknowledgements}

Thank you to Ashlie Pankonin, Sam Beech, Rose Schneider, Elisabeth Marchand, and two anonymous reviewers for comments and other help with this paper. This work was supported, in part, by a James S. McDonnell Foundation award to DB, and by grants from NIH and NSF to SC. 
Origins of Integer Representations

\begin{abstract}
Do children learn number words by associating them with perceptual magnitudes? Recent studies argue that approximate numerical magnitudes play a foundational role in the development of integer concepts. Against this, we argue that approximate number representations fail both empirically and in principle to provide the content required of integer concepts. Instead, we suggest that children's understanding of integer concepts proceeds in two phases. In the first phase, children learn small exact number word meanings by associating words with small sets. In the second phase, children learn the meanings of larger number words by mastering the logic of exact counting algorithms, which implement the successor function and Hume's principle (that 1-to-1 correspondence guarantees exact equality). In neither phase do approximate number representations play a foundational role.
\end{abstract}

$($ Word Count $=125)$ 


\section{Origins of Integer Representations}

\section{Highlights}

- A widely accepted hypothesis has emerged in Cognitive Science that an Analog Number System supplies the cognitive foundations of human arithmetic ability.

- We provide evidence from experimental psychology, human history, and the philosophy of mathematics that are difficult to explain on this hypothesis.

- We describe evidence that acquiring integer concepts depends first on capacity limit small set representations (for numbers up to $\sim 3-4$ ).

- Later learning depends critically on mastery of exact counting algorithms, and how these algorithms implement logical notions that are defined over words, individuals, and relations between them, but not over analog number representations.

- Coming to represent integers involves learning how the ordinal structure of counting encodes the successor function, and how counting implements a sequential procedure for evaluating 1-to1 correspondence and the equality of sets (i.e., Hume's principle), which allows children to overcomes the capacity limits of parallel computations of 1-to-1 correspondence that restrict small number word meanings. 
Origins of Integer Representations

\section{A Current Hypothesis Concerning the Ontogenesis of Integer Concepts}

In recent years a bold hypothesis has emerged in cognitive science, that human mathematical knowledge arises from the ability to encode the approximate cardinality of sets using the Analog Number System (ANS; Glossary). The ANS is an evolutionarily ancient system observed in non-human animals, human infants, children, and adults (1-8). Many studies assume (9-11) or explicitly argue (12-18) that the initial meanings for verbal numerals, which in adults express integer concepts, are provided by the creation of item-based associations between number words and ANS values (i.e., representations of particular numerosities).

Compatible with this hypothesis, adults exhibit mappings between verbal numerals and approximate numerical magnitudes (19-26). These mappings begin to emerge early in development (27-31) and play a role in numerical computations (1). Also, there are small but reliable correlations between children's ability to discriminate sets using the ANS and their arithmetic competence, (32-33) and some studies find that training a child's ANS can improve arithmetic performance, (34-35) though see (36-39) for critiques of these findings. Finally, the neural substrates for the ANS overlap with those deployed in arithmetic and abstract mathematics (40). These facts establish that the ANS is integrated with symbolic mathematical thought in numerate adults.

Here, however, we address a stronger thesis, which we call the "Approximate Origins Hypothesis", that ANS representations are not only associated with integer concepts, but constitute their primary ontogenetic origin, providing a conceptual foundation from which number words are learned. Critically, the studies described above do not establish when children develop mappings between numerals and the ANS, whether such mappings play a role in learning integer concepts, or even how they could. In fact, there are strong empirical (Sections II and III) and logical (Section IV) reasons to doubt this hypothesis. Evidence supports an 
Origins of Integer Representations

alternative - the "Exact Algorithms Hypothesis" (Section V) - that posits the gradual integration of exact cardinal meanings with recursive counting procedures.

\section{Empirical Challenges to the Approximate Origins Hypothesis}

Item-based associations between words and the ANS are clearly not the basis for adult integer concepts. First, although adults map the ANS to number words, these mappings are not item-based associations, but holistic Structure Mappings (Box 1), and therefore are not invariant across contexts - a critical requirement for integer concepts. In tests of random dot-array estimation, adult estimates for large sets are shifted holistically by a single instance of miscalibration (41-42). Also, when adults are shown two dot-arrays (2:1 or 3:4 ratio) and must pick which is labeled by a particular number word, they perform at or near chance, compatible with a lack of item-based associations (42). Similarly, when comparing the magnitudes of Arabic digits and dot-arrays, performance is markedly worse than when directly comparing dot-arrays to one another, suggesting that the content of numerals is not defined by associations with magnitudes (43). Finally, although the intraparietal sulcus represents both symbolic (words, digits) and non-symbolic (visual sets) number in the brain, directly correlating patterns of activation for particular quantities across these two formats finds no evidence of shared representations (44). In sum, there are no stable item-based associations between number words and ANS values that could supply integer concepts.

Evidence against the Approximate Origins Hypothesis also comes from studies of how children acquire number words. Shortly after age 2, middle-class children in the U.S. learn to recite a verbal count list to around "ten" (45-46), but lack meanings for these words (47-48). They begin by learning a meaning for "one," then months later "two", then "three" and sometimes "four" in sequence (30,46-52). This protracted period, evaluated using the Give-aNumber task, is called the Subset-Knower stage. Sometime later, between the ages of 3-and-a- 
Origins of Integer Representations

half to 4, children learn to accurately count and generate sets for any number within their count

list, at which point they are classified as Cardinal Principle knowers or CP-knowers.

\section{Box 1: Associative Mapping \& Structure Mapping}

$>$ Multiple studies have found evidence for two distinct forms of mapping between verbal numerals and ANS values. One mechanism, Associative Mapping, involves the formation of item-based associations between individual number words and corresponding ANS values, such that mappings for each number word are distinct. A second mechanism, Structure Mapping, involves the formation of a single analogical mapping between the structure of the verbal count list as a whole and a range of corresponding ANS values, such that mappings for different numbers words are causally interdependent.

$>$ Previous studies find that in adults, Associative Mappings extend up to the number 10 or 12 , while in 5 - to 7 -year-olds they extend up to 5 or 6 , such that estimation of larger numbers is supported by Structure Mapping. In support of this divide, when participants are shown two dot-arrays (e.g., 10 and 20) and asked to match a single label to one of the two (e.g., "ten"), both children and adults succeed for small numbers, but respond at or near chance for large numbers despite being equally good at discriminating these comparisons perceptually (Figure I). Also, when asked to make verbal estimates of dot-arrays up to, e.g., 350 , participants who are told that the largest array they'll see is, e.g., 750 shift their estimates for all dot-arrays except those in the small number range, which are resilient to mis-calibration.
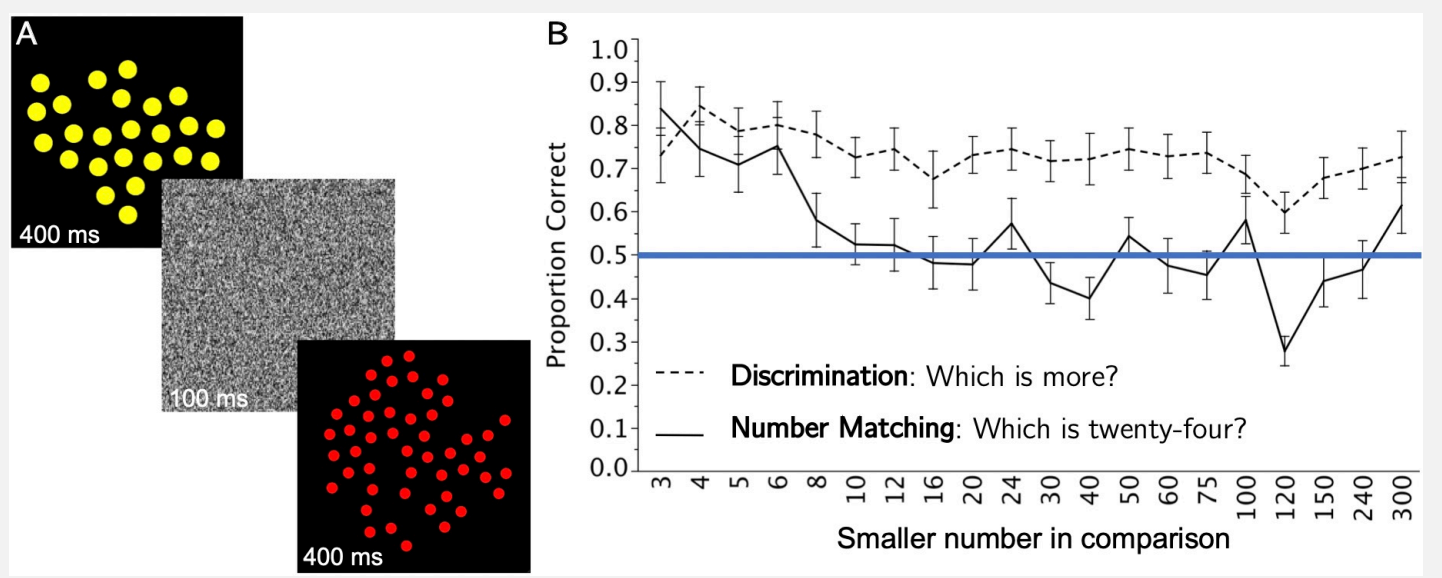

Fig I. (A) Stimuli for dot-array discrimination and number matching tasks. (B) Performance of 5 -year-old children on discrimination and number matching tasks.

$>$ These studies provide evidence for robust item-based Associative Mappings between small number words and ANS values, but Structure Mappings numbers beyond 10 . These findings are important, because they suggest that children and adults lack stable, itembased associations between individual number words and ANS values, such that if the ANS supplied the meanings of number words their meanings would be malleable and context dependent, and therefore unable to support reliable, exact, mathematical computation.

These stages provide several challenges to the Approximate Origins Hypothesis. First is

why children only learn meanings for "one" through "four" before they become CP-knowers. 
Origins of Integer Representations

Some have argued that this set-size limit may reflect preschoolers' poor ANS acuity, and that mappings for larger numbers exist but are simply not exact (12). Against this, there is abundant evidence that most children lack mappings between verbal numerals and ANS values above 3-4 until after they become CP-knowers. When asked to estimate sets from 1 to 10 , 'three-' and 'four'-knowers, as well as many CP-knowers, provide accurate responses for $1-4$. But subset knowers, as well as roughly half of young CP-knowers, provide random estimates for larger numbers $(27,30)$. Some studies claim that Subset Knowers do map numerals to the ANS $(17,27,53)$. However, as we review elsewhere (55) these findings either conflict with other similar data sets, fail to classify children's knower levels, or make analytic decisions that frame children's response errors as being compatible with ANS signatures, when in fact the tasks used are incapable of measuring such signatures. A reanalysis of past studies finds little evidence for mappings above "three" or "four" (55), and computational models of children's behavior confirm that capacity-limited stages, rather than the ANS, provide the best account of existing data (51,56-57). Given that non-human animals can learn to condition responses on specific ANS values (1-3), there is no principled reason why 2- or 3-year-olds could not learn to associate "seven" with ANS values of approximately 7, given enough evidence. However, existing evidence suggests that the ANS does not provide the numerical content of even small numerals (58; Box 2).

Eventually children do acquire mappings between larger numerals and the ANS (27-30). Five- to 7-year-olds show evidence of item-based associations between numerals and the ANS, 
Origins of Integer Representations

but only up to about 6; mappings for children's larger numerals are not item-based, but, as in adults, based on a holistic and malleable Structure Mapping (28).

\section{Box 2: Over-hypothesis about mappings of number words to ANS}

$>$ If the meanings of "one" to "four" are provided by mappings to ANS values, and these mappings play a role in the CP-induction, then CP-knowers should have an over-hypothesis that all number words express distinct ANS values. If so, CP-knowers should readily learn a mapping between other known number words (e.g., "ten") paired with sets with the labeled cardinality (e.g., 10 birds). Contrary to this, Carey et al. (58) trained 60 young CP-knowers on pairs of sets of animals (e.g., Figure I) until they could reliably identify which set had "ten". The set sizes that contrasted with 10 during training were $3,5,7,15,20$, or 30 . All children learned which of these specific training pairs had "ten". After training, children were then tested on novel stimuli-new animals and new spatial configurations with the same ratios between sets as in training, (e.g., Figure II). Although the numerical contrasts involved in each training and test pair was discriminable to children this age, children failed to identify the set of 10 on test trials (i.e., 10 vs $7,40 \%$ correct; 10 vs. $15,52 \%$ correct; 10 vs $20,52 \%$ correct; 10 vs. $30,50 \%$ correct), with no evidence of a ratio effect characteristic of the ANS. Thus, children failed to map "ten" to ANS representations of sets of 10.
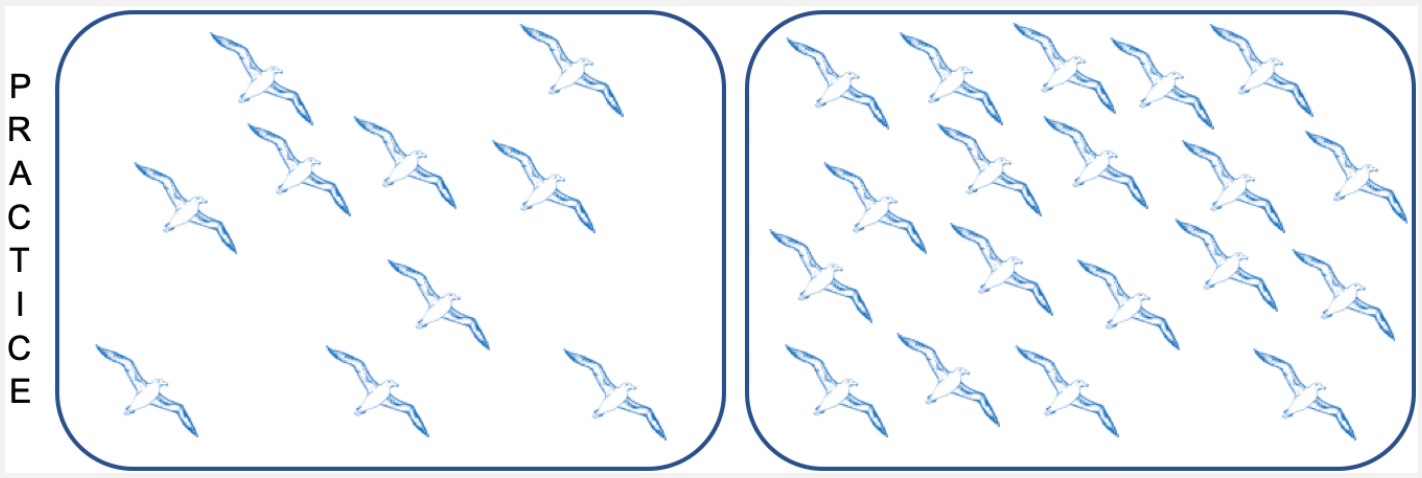

Fig I. Training associating "ten" with a set of 10 vs. 20 (mock-up of actual stimuli)
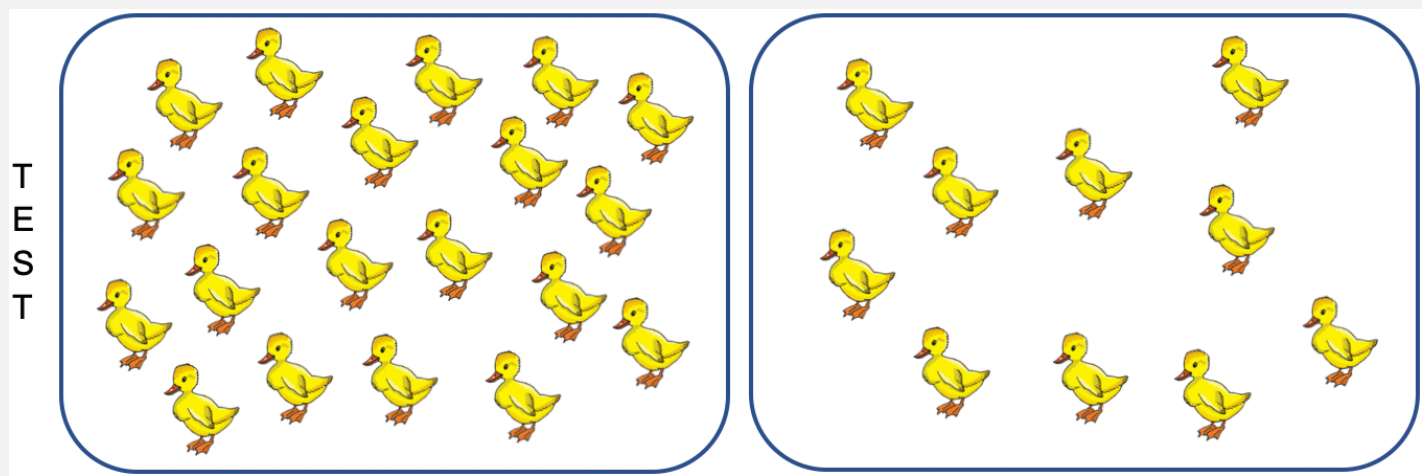

Fig II. Test trial asking children to find "ten" with sets of 10 vs. 20 (mock-up of actual stimuli) 
Origins of Integer Representations

\section{Clues from the Cultural History of Counting}

The Approximate Origins Hypothesis also confronts a broader puzzle, presented by human cultural history. If number word meanings merely reflect the content of the ANS, why would our human ancestors have bothered to create counting systems in the first place, rather than simply associate verbal labels with ANS values? The historical record suggests that humans constructed counting systems rooted in systems of 1-to-1 correspondence to overcome the noisy limits of perception, in support of equitable trade. (59-74)

Although many languages that lack counting systems have labels for numbers up to 3-4 $(63,72,75,76$; Box 3$)$, no language features a system of large approximate cardinal meanings. Many languages have singular morphology, others have dual morphology for sets of 2, and some even have trial markers for sets of 3 (63; Box 3). But no language exhibits morphology for cardinal values of 5 or more, whether exact or approximate $(63,75,76)$. When humans first created symbols for larger sets, they didn't begin by associating words with ANS magnitudes, working from these associations to derive rules of arithmetic. Instead, they began with labels for small sets, and expanded these representations with exact algorithmic systems - e.g., tally systems that place objects into 1-to-1 correspondence with arbitrary external symbols, beads, stones, or body parts $(60,62,75-83)$. For example, many tally systems begin with fingers and toes to tally the first 10-20 items, and then extend onto other body parts to tally larger sets. Although tally systems can represent numerical magnitudes, ANS representations are not implicated at any step in a tally. Instead, the fixed order of tallies in a body count guarantees that any two counts ending on a particular location (e.g., elbow) will generate equal sets. This, in turn, creates the conditions for words like "hand" and "foot" to be used as shorthand descriptions for the outcomes of counts - i.e., to represent cardinal values. For example, in certain dialects of Hup, an Amazonian language, the word for 5 translates as "one-hand", 10 as "hands-be-finish", and 20 
Origins of Integer Representations

as "feet-be-finish" (79). Similar systems have been documented in multiple languages

throughout the Amazon region, and in other regions of the world.

\section{Box 3: Languages with Bounded Number Systems}

$>$ Historically, many languages have featured words for small sets up to 2-3 despite lacking a counting system. Such languages/groups include Jarawara, Krenak, Warlbiri, Kamilarai, East Tukanoan, Aranda, Fuegian, Vedda, Botocudos, and some dialects of Nadahup $[72,75,76,83]$.

$>$ Many languages feature dual morphology, which operates like the English plural, but to designate sets of two. These include Sanskrit, Greek, Hebrew, Slovenian, Sorbian, Chakavian, Arabic, Old Irish, Old English, Old Norse, Gothic [63].

$>$ Some languages reportedly feature not only singular and dual morphology, but also trial morphology, including Larike, Ngan'gityemerri, Marrithiyel, Anindilyakwa, though the existence of so-called quadral languages with words for sets of "4" is a topic of controversy $[63,104,105]$.

$>$ In some languages, like Slovenian (Example I), some dialects have a dual and others do not, creating a natural experiment. Recent studies find that children who learn a dual dialect are quicker than non-dual learners to learn exact meanings for the words 1 and 2, even though these groups have similar amounts of training with counting [105]. One reason for this may be that when children hear the word for 2 in their input, it occurs with dual morphology, such that children who understand the dual can infer that number words used in this context encode sets of 2 .

Example I: Comparison of English \& Central Slovenian descriptions of 1 \& 2

English: One red button is lying on the table

Central Slovenian: En rdeč gumb leži na mizi

English: $\quad$ Two red buttons are lying on the table

Central Slovenian: Dva rdeča gumba ležita na mizi

In sum, over cultural evolution, like in ontogenesis, exact symbolic number

representations begin with verbal representations of small sets that are independent of counting.

A separate system, beginning with 1-to-1 tallies, extends exact representations to larger numbers.

In this respect, the historical facts paint a portrait analogous to the facts from child development.

However, as we describe below, the problem faced by children differs from that of our ancestors

in one crucial respect. The cultural construction of large exact numbers emerged from tally

systems that explicitly used 1-to-1 correspondence to establish the cardinal equivalence of sets. 
Origins of Integer Representations

In contrast, children are provided a count list that is initially learned as a meaningless routine and must gradually learn how this list implements number.

\section{Box 4. Foundations of Number}

$>$ The foundations of arithmetic are often described using a set of axioms (self-evident statements) articulated by Dedekind and Peano. These axioms include statements of equality, like "for every number, $n, n=n$ ", or "for three numbers $n, m$, and $p$, if $n=m$ and $m=p$ then $n=p$ ". They also included axioms stating that 0 (or in some versions 1 ) is a natural number, and describing a "successor function". The successor function is defined, in part, with the statement that "every natural number, $n$, has a successor $S(n)$ which is also a natural number".

$>$ In his book, The Foundations of Arithmetic, Frege (88) famously showed that the foundations of arithmetic can also be expressed using "Hume's Principle" and a secondorder logic (84-86). Hume's principle is sometimes stated as follows: Two sets $F$ and $G$ are numerically equally if for every item in $F$ there is a corresponding item in $G$ and for every item in $G$ there is a corresponding item in $F($ Fig I). In other words, two sets are equal if their members stand in perfect 1-to-1 correspondence.

$>$ These mathematical axioms were articulated thousands of years after humans first began counting, suggesting that deriving an explicit set of axioms is no easy feat. However, the counting systems of numerate adults nevertheless express content that is compatible with these axioms, suggesting that they acquire mental representations that are coextensive with them. Evidence that children's use of number words respects either one of these descriptions would provide evidence for exact cardinal integer concepts. Therefore, researchers should seek to identify when children's number words respect either Hume's principle or the successor function, and should ask which representations and learning experiences are involved in acquiring such knowledge.

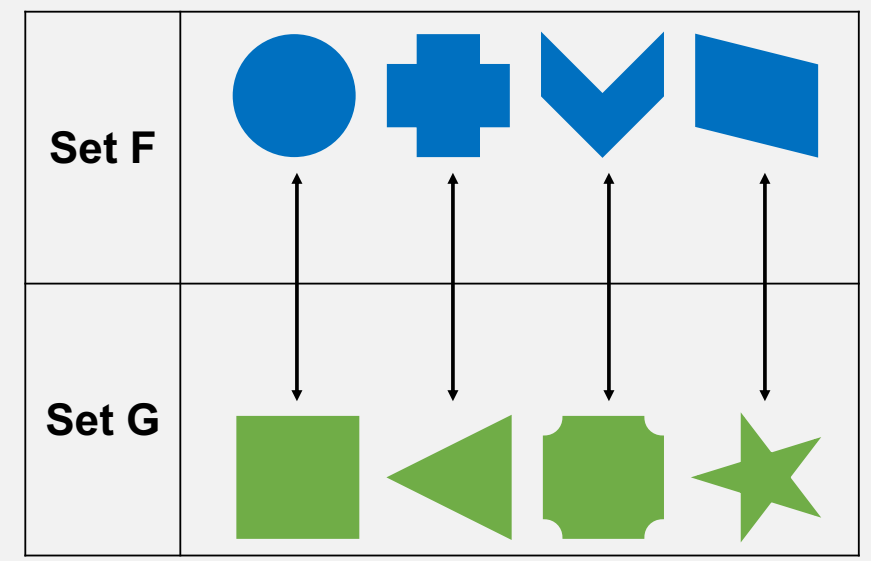

Fig I: Hume's Principle. Two sets are equal if, for each element in Set $F$ there is a corresponding element in Set G, and vice versa. 
Origins of Integer Representations

\section{Approximate Number Could Never Build Exact Number}

Despite the evidence reviewed thus far, is it possible that future studies might show that the ANS does, after all, supply the building blocks from which number word meanings are built? We believe the answer to this is a definitive "no". First, there is currently no well-articulated causal theory regarding how the ANS might play such a role. Second, we believe that no such theory is forthcoming, because the ANS lacks the content that number words express.

Formally, integers can be defined in at least two provably equivalent ways commonly discussed in the philosophy of mathematics (84-86; Box 4), though other formulations exist (8789). One approach begins with Hume's principle that 1-to-1 correspondence guarantees numerical equivalence. Counting leads to representations of numbers that respect Hume's principle, since items in a counted set are tagged in 1-to-1 correspondence with numerals that are uttered in a fixed order: Any two counts that respect 1-to-1 correspondence and end in the same numeral will therefore generate sets that are equal. The task of children is to learn how blind 1to- 1 procedures guarantee equality, and how this is related to the cardinal meanings of number words. A second way to define the integers is via the Peano axioms, which include the successor function as a primitive (i.e., every number, $N$, has a successor, $N+1$ ). Counting mirrors the successor function in its syntax, as it provides morphological rules for generating the next numeral in a verbal count sequence when one individual is added to an already enumerated set (90). As we review below, children also learn how the syntax of counting relates to cardinal increments of +1 , and thus how counting implements the successor function.

Critically, both Hume's principle and the successor function implicate representations well beyond what the ANS provides to learners (91-93). First, the ANS lacks a mechanism like 1-to-1 correspondence that can establish the exact equality of sets. The ANS is a type of Analog Magnitude System (AMS), not a system for representing relations between individuals or sets. 
Origins of Integer Representations

Thus, it can't represent 1-to-1 correspondence as a matter of principle, since 1-to-1

correspondence is a function defined over individuals, not magnitudes. Similarly, the ANS provides no way to represent the successor function. Like real or rational numbers, the ANS lacks the notion of "next number" which is required for establishing a successor function. Although 1-to-1 correspondence and the successor function can each be used to describe large numerical magnitudes, the ANS cannot explain the origin of these principles. Based on similar observations, some have argued that the ANS should not be called a number system at all, and that the word "number" should be reserved for symbolic numeral systems $(73,94-99)$. While we resist this stronger position here, given that analog representations can have numerical content, we share the conclusion of these studies that, despite being able to represent the magnitude of sets, the ANS cannot represent number in the way that the integers do.

Recognizing these problems, some proponents of the Approximate Origins Hypothesis have sought to supplement the ANS with additional machinery, e.g., by also positing innate principles that are co-extensive with the Peano axioms or Hume's principle $(100,101)$. However, once this innate knowledge is added the ANS is no longer needed to explain the origin of integer concepts, since the proposed innate principles already supply all of the needed content. What's more, these accounts still fail to explain the protracted course of number word learning, as well as the specific attested stages of learning. While it remains possible that children are endowed with innate logical knowledge of integer concepts, we currently lack evidence for this, or a theory of how children identify these representations as relevant to number words from a larger space of possible linguistic meanings. What is clear is that adding rich innate representations cannot rescue the Approximate Origins Hypothesis, but only replaces the role of the ANS in explaining the origin of integer concepts. 
Origins of Integer Representations

Any future version of the Approximate Origins Hypothesis must confront this challenge:

It should not only show how number words become associated with the ANS (or how a logic can re-describe magnitudes), but also how the ANS might provide the conceptual basis for acquiring the logic of counting and large exact number words. Short of stipulating that the ANS has such content - that fundamentally it's not a magnitude system, but a logical one - it's difficult to see how such a proposal might work.

\section{The Exact Algorithms Hypothesis}

If the Approximate Origins Hypothesis fails to explain the origin of integer concepts, how else might they arise? On our proposal - the Exact Algorithms Hypothesis - there are two distinct phases of development, analogous to two aspects of the historical record. First, children acquire small exact number word meanings by associating words with small sets, and second, they discover the logic of counting through the repeated use of its algorithms to model set representations. Neither phase implicates representations of approximate numerical magnitudes.

\section{Small Number Words}

On the Exact Algorithms Hypothesis, the meanings of small number words like "one," "two," and "three," are acquired from representations of small sets. Before children learn to count, they begin acquiring linguistic representations of sets, including quantifiers like "some" and "all", as well as singular, dual, and plural morphology (102-106). Notably, learning these verbal set representations is correlated with learning small number words. First, children who are faster to acquire the meanings of words like "some" and "all" are also faster to learn their first number words (106). Second, children learning languages with singular/plural marking are faster to begin learning number words relative to children learning languages without singular/plural agreement (107-110). Third, children learning languages with a singular/dual distinction are faster to learn the meanings of the words "one" and "two" relative to children who speak a 
Origins of Integer Representations

dialect of the same language that lacks a singular/dual distinction $(104,105)$. These data suggest that set representations are available to children early in acquisition, and that morphology and number words may draw on similar representational resources. However, they raise two important questions: (1) Why are children's first exact number representations limited to 3 or 4, and (2) What form do the non-verbal representations encoded by these words take?

Studies of preverbal infants suggest one explanation of the set limits found in early number language. Infants, like adults, can attend to multiple objects in parallel and encode them in working memory (Parallel Individuation, PI; 92,110-113). For example, if infants see 1-3 objects hidden in a box and are allowed to search and retrieve them, they continue to search until all objects are recovered. Surprisingly, performance collapses if more than 3 objects are hidden, suggesting that PI represents each individual using a distinct mental symbol in working memory and that the number of symbols that can be tokened in parallel is limited to $\sim 3$, resulting in the set size limit found in infants.

Importantly, PI representations cannot alone supply the meanings of number words. PI provides working memory models of individual things attended in the here and now, but not long-term summary representations of sets and their properties that could serve as cardinal meanings. Still, we see two ways that it might play a role. On one hypothesis (30), PI provides the representational medium for small number word meanings, and is enriched by long-term memory to represent cardinality. For example, a long-term memory model of particular sets, e.g., \{finger,finger\}, might be associated with the word "two", such that any currently attended set that can be placed in 1-to-1 correspondence with this model can be labeled "two". Alternatively, rather than providing the medium of representation, PI might provide a capacity-limited 1-to-1 system for evaluating hypotheses, which are articulated in another format, like the set representations of natural language that support singular/dual/plural, quantifiers, etc. (93). On 
Origins of Integer Representations

either account, small number word meanings are grounded in set representations that support computations like 1-to-1 correspondence. However, these representations are still not enough to explain the origin of integer concepts. For this, a system of exact counting algorithms is required.

\section{Counting, the Successor Function, \& Hume's Principle}

Although representations of small sets play an important role in the acquisition of small number words, they cannot alone explain the origin of integer concepts. First, like the ANS, they cannot express a recursive rule like the successor function. Second, they cannot be used to assess equality for numbers greater than 3-4 because they compute 1-to-1 correspondence in a parallel, capacity-limited way. Counting, in contrast, provides an external (verbal) medium with a structure that mirrors successor relations between integers, and establishes a 1-to-1 correspondence between labels and objects sequentially, which guarantees that any two counts that end at the numeral will have the same exact cardinal value. Critically, this exact algorithm doesn't impose a set-limit on 1-to-1 correspondence, since every step is computationally equivalent independent of magnitude: Each requires knowing where one is in a count (e.g., the last word counted was "twenty-five"), what comes next ("twenty-six"), and that as each number word is uttered, an additional item should be counted. Thus, counting allows children to redeploy an existing understanding of 1-to-1 correspondence in a sequential procedure that provides exact meanings for an unbounded number of numbers. The challenge is to explain how children make this developmental transition.

If the logic of number words arose from associating the count list to ANS values and noticing properties of this mapping, we might expect children to begin learning this logic early in development, since even 2-year-olds have robust ANS representations and have begun to count. However, there is substantial evidence that learning this logic hinges on becoming a CP-knower, years later, and thus on the mastery of counting algorithms. First, although children begin to 
Origins of Integer Representations

count by age 2 , they only begin to learn how counting represents the successor function after they become CP-knowers. Subset-knowers are unable to infer that adding 1 to a set of 4 results in "five", let alone that all numbers have a successor, or that numbers are infinite, and half of young CP-knowers also fail this task (114-116). When trained on the successor function, CP-knowers improve whereas Subset Knowers matched at pretest on knowledge of the successor function do not, suggesting that becoming a CP-knower is a gateway to acquiring this knowledge (86). Most likely this is because learning a verbal encoding of the successor function builds directly upon counting abilities found only in CP-knowers, not just on associations between words and magnitudes. Only by around age 5-and-a-half - 1 or 2 years after they become CP-knowers - do children exhibit evidence of having learned a fully recursive successor function that generates an infinite set of numbers, a feat which may be related to learning the grammatical rules that generate numbers in the count list itself $(93,117-119,125)$.

Similarly, there is evidence that children's appreciation of Hume's principle is related to their mastery of counting algorithms. Although children deploy various 1-to-1 procedures early in childhood (e.g., counting while pointing to objects, patty-cake, eeny-meeny-miney-mo), they lack insight that these procedures establish numerical equality. The knowledge that 1-to-1 guarantees equality (i.e., Hume's principle) is not connected to children's use of number words until after they become CP-knowers (120-123). Compatible with this, Frydman and Bryant (120) asked children to share 15 candies equally between 3 recipients, and, after allowing them to count one of these three sets, asked them how many the other recipients received, a form of transitive inference called Cardinal Extension (123). They found that children who were old enough to be CP-knowers (i.e., 4-year-olds) failed, while most 5-year-olds succeeded, indicating that children likely learned the link between 1-to-1 correspondence, equality, and number words after the CP transition. More recent studies (121-123) confirm this. For example, Sarnecka and 
Origins of Integer Representations

Wright (122) presented subset knowers and CP-knowers with sets aligned in 1-to-1

correspondence, told them the cardinal label of one set, and then asked them how many were in the second set. Only CP-knowers performed better than chance, suggesting that this is a critical prerequisite to learning how 1-to-1 correspondence relates to the cardinal meanings of number words.

\section{Integrating the Exact Algorithms and the ANS}

We began by noting that exact symbolic representations of number are ultimately integrated with the ANS, and that this integration is important to using numbers in mathematical reasoning. Historically, it's likely that humans invented exact counting algorithms precisely because they observed, via their senses, that sets differed in numerical magnitudes, but realized these percepts were too noisy to be reliable tools of equitable trade and record keeping (124). Although integer concepts aren't built from the ANS - and couldn't be - the integration of these systems is both natural and beneficial to human numerical reasoning and social interaction.

The history of mathematics provides multiple examples of how representing reality in multiple ways enhances understanding. For example, Descartes' integration of graphical and algebraic representations of mathematical functions demonstrated that although either of these formats of representation can represent functions, each makes different aspects of the same reality more or less salient and available to different types of computations. Mapping exact symbolic systems to magnitudes adds intuitive content and allows explicit symbols to inherit the computational affordances of the magnitude system (e.g., numerical comparison and approximate arithmetic). When symbolic systems are not mapped to magnitudes, they are sometimes difficult to use, explaining why it takes time to transition from Celsius to Fahrenheit, to recognize good vs. bad deals in a foreign currency, or to reason in a novel counting system, like binary notation $(125,126)$. Although approximate magnitudes don't explain where exact 
Origins of Integer Representations

symbols come from, they are often the things that we describe when we use numerals, and play a central role in giving numerals their intuitive connection to the world.

\section{Concluding Remarks}

Adults associate number words with the ANS via a holistic Structure Mapping, which lacks stable, item-based, cardinal meanings. Neither small number words nor counting, however, implicate the ANS. Developmental and anthropological data suggest that humans are predisposed to learn linguistic forms describing small sets, and that larger cardinal meanings depend on constructing a system of exact counting algorithms. Current work suggests that learning integer concepts depends on learning counting procedures, and integrating them with computations like 1-to-1 correspondence and the successor function. Counting procedures are critical because repeated acts of counting create a workspace in which children can learn relations between numbers, objects, and sets.

Many Outstanding Questions remain. First, given that children begin counting many months earlier, it remains uncertain why they must become CP-knowers before they learn that counting offers a sequential procedure for assessing 1-to-1 correspondence and equality, and is governed by a successor function. Is becoming a CP-knower purely a matter of learning a blind counting procedure, or does it mark a moment of conceptual insight? Second, when do children integrate the ANS with counting, and can such mappings be trained prior to mastery of counting? Could learning mappings play a role in later stages of counting mastery - e.g., to learn that numbers later in the count list denote greater quantities? Finally, how can the complex developmental facts described here be captured by formal computational models, to afford precise formulation and assessment of hypotheses? Previous models (127) demonstrate that integers can be built from primitives including set representations, a count list, a quantificational logic, and input that pairs number words with cardinal values. However, as argued elsewhere, 
Origins of Integer Representations

much work remains to align such models with existing developmental evidence (128). A future priority is the development of models tested against rich developmental data, which confront how logical representations are implemented in the mind and deployed in learning. 
Origins of Integer Representations 
Origins of Integer Representations

\section{Outstanding Questions}

- Is becoming a CP-knower purely a matter of learning yet another blind counting procedure, or does it mark a moment of conceptual insight in which children understand something new about how numbers represent cardinality? If so, what?

- How does counting come to respect Hume's principle in development, and is this related to mastery of how counting encodes the successor function? Or are these causally distinct in development?

- Many studies find no mappings to the ANS before the CP-knower stage, and failures to train mappings even in CP-knowers. When is the ANS integrated with counting, and are there conditions under which such mappings can reliably be trained prior to mastery of counting? At what point in the mastery of cardinal meanings and of counting do children first show evidence of holistic Structure Mappings?

- In what ways can computational modeling and cognitive neuroscience illuminate our studies of how children come to represent integers? 
Origins of Integer Representations

\section{References}

[1] Dehaene, S. (1997). The number sense: how the mind creates mathematics. New York: Oxford. University Press.

[2] Gallistel, C. R. (1990). The organization of learning. Cambridge, MA, US: The MIT Press.

[3] Platt, J.R., \& Johnson, D. M. (1971). Localization of position within a homogeneous behavior chain: Effects of error contingencies. Learning and Motivation, 2, 386-414.

[4] Brannon, E. M., \& Terrace, H. S. (1998). Ordering of the numerosities by monkeys. Science, 282, 746-749.

[5] Brannon, E. M. (2000). Representation of the numerosities 1-9 by rhesus macaques (Macaca mulatta). Journal of Experimental Psychology: Animal Behavior Processes, 26(1), 31-49.

[6] Xu, F., \& Spelke, E. S. (2000). Large number discrimination in 6-month-old infants. Cognition, 74(1), B1-B11.

[7] Barth, H., Kanwisher, N., \& Spelke, E. (2003). The construction of large number representations in adults. Cognition, 86(3), 201-221.

[8] Halberda, J., \& Feigenson, L. (2008). Developmental change in the acuity of the" Number Sense": The Approximate Number System in 3-, 4-, 5-, and 6-year-olds and adults. Developmental Psychology, 44(5), 1451-1465.

[9] Bugden, S., \& Ansari, D. (2011). Individual differences in children's mathematical competence are related to the intentional but not automatic processing of Arabic numerals. Cognition, 118(1), 3244.

[10] Odic, D., Le Corre, M., \& Halberda, J. (2015). Children's mappings between number words and the approximate number system. Cognition, 138, 102-121.

[11] Sasanguie, D., Göbel, S. M., Moll, K., Smets, K., \& Reynvoet, B. (2013). Approximate number sense, symbolic number processing, or number-space mappings: What underlies mathematics achievement? Journal of experimental child psychology, 114(3), 418-431.

[12] Dehaene, S. (2009). Origins of mathematical intuitions. Annals of the New York Academy of Sciences, 1156(1), 232-259.

[13] Gallistel, C. R., \& Gelman, R. (2000). Non-verbal numerical cognition: From reals to integers. Trends in Cognitive Sciences, 4(2), 59-65

[14] Piazza, M. (2011). Neurocognitive start-up tools for symbolic number representations. In Space, Time and Number in the Brain (pp. 267-285).

[15] Starr, A., Libertus, M. E., \& Brannon, E. M. (2013). Number sense in infancy predicts mathematical abilities in childhood. Proceedings of the National Academy of Sciences, 110(45), 18116-18120.

[16] Verguts, T., \& Fias, W. (2004). Representation of Number in Animals and Humans: A Neural Model. Journal of Cognitive Neuroscience, 16(9), 1493-1504.

[17] Wagner, J. B., \& Johnson, S. C. (2011). An association between understanding cardinality and analog magnitude representations in preschoolers. Cognition, 119(1), 10-22.

[18] Nieder, A. (2017). Number faculty is rooted in our biological heritage. Trends in cognitive sciences, 21(6), 403-404.

[19] Dehaene, S., \& Marques, J. F. (2002). Cognitive Neuroscience: Scalar variability in price estimation and the cognitive consequences of switching to the euro. The Quarterly Journal of Experimental Psychology Section A, 55(3), 705-731.

[20] Gallistel, C.R., \& Gelman, R. (2005). Mathematical Cognition. In K.J. Holyaok \& R.G. Morrison (Eds.), The Cambridge handbook of thinking and reasoning (pp. 559-588). Cambridge: Cambridge University Press.

[21] Hollingsworth, W. H., Simmons, J. P., Coates, T. R., \& Cross, H. A. (1991). Perceived numerosity as a function of array number, speed of array development, and density of array items. Bulletin of 
Origins of Integer Representations

the Psychonomic Society, 29(5), 448-450.

[22] Indow, T., \& Ida, M. (1977). Scaling of dot numerosity. Perception \& Psychophysics, 22(3), 265276.

[23] Krueger, L. E. (1972). Perceived numerosity. Perception \& Psychophysics, 11(1), 5-9.

[24] Krueger, L. E. (1982). Single judgments of numerosity. Perception \& Psychophysics, 31(2), 175182.

[25] Krueger, L. E. (1984). Perceived numerosity: A comparison of magnitude production, magnitude estimation, and discrimination judgments. Perception \& Psychophysics, 35(6), 536-542.

[26] Logie, R. H., \& Baddeley, A. D. (1987). Cognitive processes in counting. Journal of Experimental Psychology: Learning, Memory, and Cognition, 13(2), 310-326.

[27] Gunderson, E. A., Spaepen, E., \& Levine, S. C. (2015). Approximate number word knowledge before the cardinal principle. Journal of Experimental Child Psychology, 130, 35-55.

[28] Sullivan, J., \& Barner, D. (2014). Inference and association in children's early numerical estimation. Child Development, 85(4), 1740-1755.

[29] Siegler, R. S., \& Opfer, J. E. (2003). The Development of Numerical Estimation: Evidence for Multiple Representations of Numerical Quantity. Psychological Science, 14(3), 237-250.

[30] Le Corre, M., \& Carey, S. (2007). One, two, three, four, nothing more: An investigation of the conceptual sources of the verbal counting principles. Cognition, 105(2), 395-438.

[31] Berteletti, I., Lucangeli, D., Piazza, M., Dehaene, S., \& Zorzi, M. (2010). Numerical estimation in preschoolers. Developmental Psychology, 46(2), 545-551.

[32] De Smedt, B., Noël, M. P., Gilmore, C., \& Ansari, D. (2013). How do symbolic and non-symbolic numerical magnitude processing skills relate to individual differences in children's mathematical skills? A review of evidence from brain and behavior. Trends in Neuroscience and Education, 2(2), 48-55.

[33] Schneider, M., Beeres, K., Coban, L., Merz, S., Susan Schmidt, S., Stricker, J., \& De Smedt, B. (2017). Associations of non-symbolic and symbolic numerical magnitude processing with mathematical competence: A meta-analysis. Developmental Science, 20(3), e12372.

[34] Park, J., \& Brannon, E. M. (2013). Training the approximate number system improves math proficiency. Psychological Science, 24(10), 2013-2019.

[35] Hyde, D. C., Khanum, S., \& Spelke, E. S. (2014). Brief non-symbolic, approximate number practice enhances subsequent exact symbolic arithmetic in children. Cognition, 131(1), 92-107.

[36] Szücs, D., \& Myers, T. (2017). A critical analysis of design, facts, bias and inference in the approximate number system training literature: A systematic review. Trends in Neuroscience and Education. Vol, pages.

[37] Inglis, M., Batchelor, S., Gilmore, C., \& Watson, D. G. (2017). Is the ANS linked to mathematics performance? The Behavioral and Brain Sciences.

[38] Mussolin, C., Nys, J., Leybaert, J., \& Content, A. (2012). Relationships between approximate number system acuity and early symbolic number abilities. Trends in Neuroscience and Education, 1(1), 21-31.

[39] Lyons, I. M., Bugden, S., Zheng, S., De Jesus, S., \& Ansari, D. (2018). Symbolic number skills predict growth in nonsymbolic number skills in kindergarteners. Developmental Psychology

[40] Alalric, M., \& Dehaene, S. (2016). Origins of the brain networks for advanced mathematics in expert mathematicians. Proceedings of the National Academy of Sciences, 113 (18), 4909-4917.

[41] Izard, V., \& Dehaene, S. (2008). Calibrating the mental number line. Cognition, 106(3), 1221-1247.

[42] Sullivan, J., \& Barner, D. (2013). How are number words mapped to approximate magnitudes? The Quarterly Journal of Experimental Psychology, 66(2), 389-402.

[43] Lyons, I. M., Ansari, D., \& Beilock, S. L. (2012). Symbolic estrangement: Evidence against a strong association between numerical symbols and the quantities they represent. Journal of 
Origins of Integer Representations

Experimental Psychology: General, 141(4), 635-641.

[44] Lyons, I., Ansari, D. and Beilock, S. (2014). Qualitatively different coding of symbolic and nonsymbolic numbers in the human brain. Human Brain Mapping, 36(2), pp.475-488.

[45] Gelman, R., \& Gallistel, C. R. (1978). The child's understanding of number. Cambridge, MA: Harvard University Press.

[46] Fuson, K. C., Richards, J., \& Briars, D. J. (1982). The Acquisition and Elaboration of the Number Word Sequence. In C. J. Brainerd (Ed.), Children's Logical and Mathematical Cognition:

Progress in Cognitive Development Research (pp. 33-92), New York, NY: Springer New York.

[47] Wynn, K. (1990). Children's understanding of counting. Cognition, 36(2), 155-193.

[48] Wynn, K. (1992). Children's acquisition of the number words and the counting system. Cognitive Psychology, 24(2), pp.220-251.

[49] Briars, D., \& Siegler, R. S. (1984). A featural analysis of preschoolers' counting knowledge. Developmental Psychology, 20(4), 607-618.

[50] Le Corre, M., Van de Walle, G., Brannon, E. M., \& Carey, S. (2006). Re-visiting the competence/performance debate in the acquisition of the counting principles. Cognitive Psychology, 52(2), 130-169.

[51] Sarnecka, B. W., \& Lee, M. D. (2009). Levels of number knowledge during early childhood. Journal of Experimental Child Psychology, 103(3), 325-337.

[52] Huang, Y. T., Spelke, E., \& Snedeker, J. (2010). When is four far more than three? Children's generalization of newly acquired number words. Psychological Science, 21(4), 600-606.

[53] Odic, D., Le Corre, M., \& Halberda, J. (2015). Children's mappings between number words and the approximate number system. Cognition, 138, 102-121.

[55] Wagner, K., Chu, J., \& Barner, D. (2019). Do children's number words begin noisy? Developmental Science, 22(1), e12752.

[56] Lee, M. D., \& Sarnecka, B. W. (2010). A model of knower-level behavior in number concept development. Cognitive science, 34(1), 51-67.

[57] Lee, M. D., \& Sarnecka, B. W. (2011). Number-knower levels in young children: Insights from Bayesian modeling. Cognition, 120(3), 391-402.

[58] Carey, S., Shusterman A., Haward, P., and Distefano, R. (2017). Do Analog Number Representations Underlie the Meanings of Young Children's Verbal Numerals? Cognition, 168, $243-255$.

[59] Schmandt-Besserat, D. (1980). The Envelopes That Bear the First Writing. Technology and Culture, 21(3), 357-385.

[60] Schmandt-Besserat, D. (1983). " BA" Guide to Artifacts: Tokens \& Counting. The Biblical Archaeologist, 46(2), 117-120.

[61] Mattessich, R. (2012). The Beginnings of Accounting and Accounting Thought: Accounting Practice in the Middle East (8000 BC to 2000 BC) and Accounting Thought in India (300 BC and the Middle Ages). Routledge.

[62] Ifrah, G. (2000). The Universal History of Numbers: From Prehistory to the Invention of the Computer. Translated by D. Vellos, E. F. Harding, S. Wood, \& I. Monk, New York: John Wiley \& Sons.

[63] Corbett, G. (2000). Number. Cambridge: Cambridge University Press.

[64] Coppola, M., Spaepen, E., \& Goldin-Meadow, S. (2013). Communicating about quantity without a language model: Number devices in homesign grammar. Cognitive Psychology, 67(1-2), 1-25.

[65] Spaepen, E., Coppola, M., Spelke, E. S., Carey, S. E., \& Goldin-Meadow, S. (2011). Number without a language model. Proceedings of the National Academy of Sciences, 108(8), 3163-3168.

[66] Spaepen, E., Coppola, M., Flaherty, M., Spelke, E., \& Goldin-Meadow, S. (2013). Generating a lexicon without a language model: Do words for number count? Journal of Memory and 
Origins of Integer Representations

Language, 69(4), 496-505.

[67] Dixon, R. M., Dixon, R. M. W., \& Vogel, A. R. (2004). The Jarawara Language of Southern Amazonia. Oxford University Press on Demand.

[68] Loukotka, C. (1955). Les Indiens Botocudo et leur langue. Pa'nstwowe Wydawnictwo Naukowe.

[69] Hale, K. (1975). Gaps in grammar culture. Lisse: Peter de Ridder Press.

[70] Sommerfelt, A. (1938). La langue et la société: caractères sociaux d'une langue de type archaïque. Oslo: London : Aschehoug, Kegan Paul, Trench, Trübner.

[71] Tylor, E. B. (1871). Primitive Culture: Researches Into the Development of Mythology, Philosophy, Religion, Art, and Custom. London: Murray.

[72] Bowern, C., \& Zentz, J. (2012). Diversity in the numeral systems of Australian languages. Anthropological Linguistics, 54(2), 133-160.

[73] Núñez, R. E. (2017). Is there really an evolved capacity for number? Trends in cognitive sciences, $21(6), 409-424$.

[74] Lancy, D. F. (1983). Cross-cultural studies in cognition and mathematics.

[75] Epps, P., Bowern, C., Hansen, C. A., Hill, J. H., \& Zentz, J. (2012). On numeral complexity in hunter-gatherer languages. Linguistic Typology, 16(1), 41-109.

[76] Hammarström, H. (2010). Rarities in numeral systems. Rethinking universals: How rarities affect linguistic theory, 45, 11-53.

[77] Cushing, F. H. (1892). Manual Concepts: A Study of the Influence of Hand-Usage on CultureGrowth, American Anthropologist, 5(4), 289-318.

[78] Hawtrey, S. H. (1901). The Lengua Indians of the Paraguayan Chaco. Journal of the Anthropological Institute of Great Britain and Ireland, 280-299.

[79] Epps, P. (2006). Growing a numeral system: The historical development of numerals in an Amazonian language family. Diachronica International Journal for Historical Linguistics. Founded by E.F.K. Koerner, General Editor, 1984-2001, 23(2), pp.259-288.

[80] Saxe, G. B. (1981). Body parts as numerals: A developmental analysis of numeration among the Oksapmin in Papua New Guinea. Child development, 306-316.

[81] Lancy, D. F. (1981). The indigenous mathematics project: An overview. Educational Studies in Mathematics, 12(4), 445-453.

[82] Wassmann, J., \& Dasen, P. R. (1994). Yupno number system and counting. Journal of CrossCultural Psychology, 25(1), 78-94.

[83] Comrie, B. (2011). Typology of numeral systems. Numeral types and changes worldwide. Trends in Linguistics. Studies and monographs, 118.

[84] Decock, L. (2008). The conceptual basis of numerical abilities: One-to-one correspondence versus the successor relation. Philosophical Psychology, 21(4), 459-473.

[85] Heck, R. G. (1995). Frege's principle. In From Dedekind to Gödel (pp. 119-142). Springer, Dordrecht.

[86] Wright, C. (1983). Frege's Conception of Numbers as Objects, Aberdeen University Press, Aberdeen.

[87] Von Neumann, J. (1923). On the introduction of transfinite numbers. reprinted in van Heijenoort (1967), 346-354.

[88] Frege, G. (1968). The foundations of arithmetic: A logico-mathematical enquiry into the concept of number. Northwestern University Press.

[89] Church, A. (1932). A set of postulates for the foundation of logic. Annals of mathematics, 346-366.

[90] Ionin, Tania, and Ora Matushansky. 2019. Cardinals: The syntax and semantics of cardinalcontaining expressions. Cambridge, MA: MIT Press.

[91] Carruthers, P., Laurence, S. and Stich, S. (2005). The Innate mind. New York: Oxford University Press. 
Origins of Integer Representations

[92] Carey, S. (2009). The Origin of Concepts. New York: Oxford University Press.

[93] Barner, D. (2017). Language, procedures, and the non-perceptual origin of number word meanings. Journal of child language, 44(3), 553-590.

[94] Leibovich, T., \& Ansari, D. (2016). The symbol-grounding problem in numerical cognition: A review of theory, evidence, and outstanding questions. Canadian Journal of Experimental Psychology = Revue Canadienne de Psychologie Expérimentale, 70(1), 12-23.

[95] Leibovich, T., Katzin, N., Harel, M., \& Henik, A. (2016). From 'sense of number' to 'sense of magnitude' - The role of continuous magnitudes in numerical cognition. Behavioral and Brain Sciences, pp. 1-62

[96] Walsh, V. (2003). A theory of magnitude: common cortical metrics of time, space and quantity. Trends in cognitive sciences, 7(11), 483-488.

[97] Leibovich et al. 2017, BBS and Leibovich \& Ansari, 2016, Canadian Journal of Experimental Psychology

[98] Lourenco, S. F., \& Longo, M. R. (2010). General magnitude representation in human infants. Psychological Science, 21(6), 873-881.

[99] Brannon, E. M. (2006). The representation of numerical magnitude. Current opinion in neurobiology, 16(2), 222-229.

[100] Gallistel, C. R., \& Gelman, R. (1992). Preverbal and verbal counting and computation. Cognition, 44(1-2), 43-74.

[101] Leslie, A. M., Gelman, R., \& Gallistel, C. R. (2008). The generative basis of natural number concepts. Trends in cognitive sciences, 12(6), 213-218.

[102] Li, P., Ogura, T., Barner, D., Yang, S. J., \& Carey, S. (2009). Does the conceptual distinction between singular and plural sets depend on language?. Developmental psychology, 45(6), 1644.

[103] Barner, D., Thalwitz, D., Wood, J., Yang, S. J., \& Carey, S. (2007). On the relation between the acquisition of singular-plural morpho-syntax and the conceptual distinction between one and more than one. Developmental science, 10(3), 365-373.

[104] Almoammer, A., Sullivan, J., Donlan, C., Marušič, F., O’Donnell, T., \& Barner, D. (2013). Grammatical morphology as a source of early number word meanings. Proceedings of the National Academy of Sciences, 110(46), 18448-18453.

[105] Marušič, F., Plesničar, V., Razboršek, T., Sullivan, J., \& Barner, D. (2016). Does grammatical structure accelerate number word learning? Evidence from learners of dual and non-dual dialects of Slovenian. PloS one, 11(8), e0159208.

[106] Barner, D., Chow, K., \& Yang, S. J. (2009). Finding one's meaning: A test of the relation between quantifiers and integers in language development. Cognitive psychology, 58(2), 195-219.

[107] Sarnecka, B. W., Kamenskaya, V. G., Yamana, Y., Ogura, T., \& Yudovina, Y. B. (2007). From grammatical number to exact numbers: Early meanings of 'one', 'two', and 'three' in English, Russian, and Japanese. Cognitive psychology, 55(2), 136-168.

[108] Le Corre, M., Li, P., Huang, B. H., Jia, G., \& Carey, S. (2016). Numerical morphology supports early number word learning: Evidence from a comparison of young Mandarin and English learners. Cognitive Psychology, 88, 162-186.

[109] Barner, D., Libenson, A., Cheung, P., \& Takasaki, M. (2009). Cross-linguistic relations between quantifiers and numerals in language acquisition: Evidence from Japanese. Journal of Experimental Child Psychology, 103(4), 421-440.

[110] Feigenson, L., Dehaene, S., \& Spelke, E.S. (2004). Core systems of number. Trends in Cognitive Sciences, 8, 7, 307-314.

[111] Cantrell, L., \& Smith, L. B. (2013). Open questions and a proposal: A critical review of the evidence on infant numerical abilities. Cognition, 128(3), 331-352. 
Origins of Integer Representations

[112] Feigenson, L., Carey, S., \& Hauser, M. (2002). The representations underlying infants' choice of more: Object files versus analog magnitudes. Psychological science, 13(2), 150-156.

[113] Feigenson, L., \& Carey, S. (2005). On the limits of infants' quantification of small object arrays. Cognition, 97(3), 295-313.

[114] Sarnecka, B., \& Carey, S. (2008). How counting represents number: What children must learn and when they learn it. Cognition, 108(3), 662-674.

[115] Spaepen, E., Gunderson, E. A., Gibson, D., Goldin-Meadow, S., \& Levine, S. C. (2018). Meaning before order: Cardinal principle knowledge predicts improvement in understanding the successor principle and exact ordering. Cognition, 180, 59-81.

[116] Davidson, K., Eng, K., \& Barner, D. (2012). Does learning to count involve a semantic induction? Cognition, 123(1), 162-173.

[117] Secada, W. G., Fuson, K. C., \& Hall, J. W. (1983). The transition from counting-all to counting-on in addition. Journal for Research in Mathematics Education, 47-57.

[118] Cheung, P., Rubenson, M., \& Barner, D. (2017). To infinity and beyond: Children generalize the successor function to all possible numbers years after learning to count. Cognitive Psychology, 92, 22-36.

[119] Hartnett, P., \& Gelman, R. (1998). Early understandings of numbers: Paths or barriers to the construction of new understandings? Learning and instruction, 8(4), 341-374.

[120] Frydman, O., \& Bryant, P. (1988). Sharing and the understanding of number equivalence by young children. Cognitive Development, 3(4), 323-339.

[121] Condry, K. F., \& Spelke, E. S. (2008). The development of language and abstract concepts: The case of natural number. Journal of Experimental Psychology: General, 137, 22-?.

[122] Sarnecka, B. W., \& Wright, C. E. (2013). The idea of an exact number: Children's understanding of cardinality and equinumerosity. Cognitive science, 37(8), 1493-1506.

[123] Muldoon, K., Lewis, C., \& Freeman, N. H. (2003). Putting counting to work: Preschoolers' understanding of cardinal extension. International Journal of Educational Research, 39(7), 695 718.

[124] Barner, D. (in press). Numerical symbols as explanations of subjective human experience. In M. Sera \& M. Koenig (Eds.), Minnesota Symposia in Child Psychology, Volume 39.

[125] Marques, J. F., \& Dehaene, S. (2004). Developing intuition for prices in euros: rescaling or relearning prices? Journal of Experimental Psychology: Applied, 10(3), 148.

[126] Giaquinto, M. (2006). Mental number lines. The Innate Mind, 2, 112-130.

[127] Piantadosi, S. T., Tenenbaum, J. B., \& Goodman, N. D. (2012). Bootstrapping in a language of thought: a formal model of numerical concept learning. Cognition, 123, 199-217.

[128] Carey, S. (2015). Why theories of concepts should not ignore the problem of acquisition. In E. Margolis \& S. Laurence (eds). Concepts: New Directions. Cambridge: MIT Press, 415-454. 
Origins of Integer Representations

\section{Glossary}

1-to-1 Correspondence: A function relating two sets, such that for every element in one set, there's also an element in the other set. Hume's Principle states that two sets are equal in number if they exhibit 1-to-1 correspondence.

Analog Number System (ANS): A perceptual encoding system which takes as input a sensory representation of a set of individuals and creates an analog symbol that is approximately proportional to the cardinal value of the set. If lengths served as ANS symbols, _, _ , and , could be ANS symbols, representing 1,2, 5 and 10,

respectively. The mental symbols that correspond to these external analog symbols are called "ANS values" in the text. A signature of the ANS, as of all Analog Magnitude Systems, is that discriminability of magnitudes accords with Weber's law.

Analog Magnitude System (AMS): Humans discriminate magnitudes across many dimensions of experience including perceived brightness, loudness, length, surface area, density, and intensity of pain. In each case, the ability to discriminate magnitudes is ratio-dependent, and therefore governed by Weber's Law. These facts suggest that humans represent diverse dimensions of experience using a common format of representation, an observation which has led some to claim that all magnitude discrimination is supported by a single Generalized Magnitude System (96-99). However, the systems differ with respect to their content, with the result that they take different stimuli as inputs and support different inferences. For the purposes of this paper, we individuate systems according to differences in content, and therefore refer to the ANS as one of many AMS systems.

Cardinal Extension: The ability to recognize that if a set $F$ has a particular cardinal label (e.g., "ten"), then all other sets that stand in 1-to-1 correspondence with $F$ should be extended the same label (i.e., sets in 1-to-1 correspondence have the same cardinal label). 
Origins of Integer Representations

Cardinal Principle Knower (CP-Knower): A child who can reliably give sets larger than 3-4 in the Give-a-Number task by virtue of counting. Although this behavior was interpreted by early studies as evidence that children have learned the Cardinal Principle - i.e., that the last number used when accurately counting a set denotes the exact cardinal value of the set - more recent studies suggest that CP-knowers may initially deploy a blind procedure.

Cardinal Meaning: The number of items in a set is its cardinality. A cardinal meaning is the number of items denoted by a number word.

Integer Concepts: An integer is a whole number (i.e., doesn't include fractions or real numbers). Integer concepts are mental representations that encode integers. Integer concepts are distinct from number words, which are, in some instances, labels for integer concepts.

Give-a-Number Task: A task that tests (1) which words children have assigned cardinal values, and (2) whether they have acquired the Cardinal Principle. Children are given a set of objects (e.g., 10 fish), and are asked repeatedly to give different numbers - e.g., "Can you give me two fish?". The task is used to assign children "knower levels" as follows: A child is, e.g., a "two"knower if they correctly give 2 at least $2 / 3$ times when asked for "two", and if, when they give 2 this is in response to the number word "two" on at least $2 / 3$ of trials (e.g., they don't just give 2 for everything).

Ontogenetic Origin: The word "ontogenesis" refers to the development of an organism within its lifetime. An ontogenetic origin is an early emerging structure, biological substrate, or representational format that plays a causal role in developmental change.

Parallel Individuation (PI): A system dedicated to representing individuals (e.g., objects).

When a small set is attended, a single mental symbol is created for each object and is stored in a working memory model of the collection. PI is capacity limited—-both infants' and adults' attention and working memory are limited by the number of individuals in a set. By 10-months 
Origins of Integer Representations

of age, preverbal infants successfully track up to 3 simple objects at a time, but fail to track larger sets of 4 or more.

Subset-Knower: Children who can respond correctly on the Give-a-Number task for a subset of numbers, and who don't yet know the Cardinal Principle. 